\title{
HUBUNGAN JUMLAH OBAT YANG DIRESEPKAN DENGAN \\ POTENSIAL PENGGUNAAN OBAT YANG TIDAK TEPAT PADA \\ PASIEN PENYAKIT GINJAL KRONIS DI RS PKU MUHAMMADIYAH YOGYAKARTA
}

\section{RELATIONSHIP BETWEEN NUMBER OF DRUGS PRESCRIBING WITH POTENTIALLY INAPROPRIATE MEDICATION USE IN CKD PATIENTS IN PKU MUHAMMADIYAH YOGYAKARTA HOSPITAL}

\author{
Evi Mulyani, Endang Darmawan, Mustofa \\ ${ }^{1}$ Fakultas Pasca Sarjana, Universitas Ahmad Dahlan \\ Jl Prof. Dr. Soepomo, Janturan, Yogyakarta, Telp. (0274) 379418 \\ Email:evi.muly4ni@gmail.com
}

Submitted : 22-05-2015 Reviewed : 25-05-2015

Accepted: 24-11-2015

\begin{abstract}
ABSTRAK
Penurunan fungsi fisiologis tubuh terkait usia meyebabkan beberapa masalah kesehatan pada usia lanjut, sehingga masalah pengobatan pada usia lanjut juga tidak jarang ditemukan seperti polifarmasi dan potentially inappropriate medication (PIMs). Tujuan penelitian ini untuk mengetahui hubungan jumlah obat yang diresepkan dengan PIMs pada pasien usia lanjut yang menderita penyakit ginjal kronis di RS PKU Muhammadiyah Yogyakarta. Identifikasi PIMs dilakukan dengan kriteria STOPP, sedangkan jumlah obat yang diresepkan dilihat berdasarkan buku kendali obat pasien. Untuk mengkaji riwayat kesehatan pasien dilakukan wawancara dan penelusuran rekam medik. Karakteristik pasien di analisa secara deskriptif, sedangkan korelasi antar variabel dianalisis dengan uji chi square. Dari 53 sampel, teridentifikasi PIMs sebesar 17\% dengan rata-rata sampel mendapatkan satu PIMs. Sedangkan dari 410 obat yang diresepkan rata-rata pasien menerima obat 8 obat (>6). Hasil uji bivariat menunjukan bahwa tidak terdapat hubungan yang signifikan antara jumlah obat yang diresepkan dengan PIMs.
\end{abstract}

Kata kunci : Jumlah obat yang diresepkan, PIMs, CKD.

\begin{abstract}
Age-related decrease of physiological function caused some healt problem in elderly, so the problem of treatment in the elderly is also not uncommon found as polypharmacy and Potentially Inappropriate medication (PIMs). The purpose of this study to determine the relationship of the number of drug prescribed with PIMs in elderly patients with CKD in PKU Muhammadiyah Yogyakarta Hospital. PIMs identification by STOPP criteria, while the number of drugs prescribed seen by drugs control books. To assess the patient's medical history by interviews and search records. Patient characteristics were analyzed descriptively, correlations between variables were analyzed with chi square test. From 53 samples, PIMs identified 17\% and average one sample got one PIMs, while of the 410 drugs that prescribed average patient receiving 8 drugs $(>6)$. Bivariate test results showed that no significant relationship between the number of drug prescribed with PIMs.
\end{abstract}

Keywords: number of drugs prescribed, PIMs, CKD 


\section{PENDAHULUAN}

Menurut world healt organisation (WHO) dari tahun 2000 sampai 2025, Indonesia akan mengalami peningkatan penduduk usia lanjut sebesar $41,4 \%$, yang merupakan peningkatan tertinggi di dunia. Pada tahun 2012 sensus nasional menunjukan salah satu wilayah provinsi di Indonesia yang mempunyai penduduk usia lanjut terbesar adalah Yogyakarta dengan persentase $(13,04 \%)$ sehingga masalah kesehatan pada populasi ini menjadi hal utama yang harus diperhatikan (Kemenkes RI, 2013).

Masalah kesehatan terkait usia sering ditemukan pada pasien usia lanjut, sehingga menjadi perhatian yang cukup serius dalam penangananya. Bebrapa penyakit kronis yang biasa diderita pasien usia lanjut adalah hipertensi, diabetes melitus, gagal jantung, penyakit paru obstruktif, muskuloskeletal, dan digesti (Yenni \& Herwana, 2006). Selain itu CKD juga merupakan penyakit kronis yang dapat disebabkan karena adanya penurunan fungsi fisiologis secara alami pada pasien usia lanjut, prevalensi CKD pada pasien usia lanjut di beberapa negara seperti Amerika (Hoerger et al., 2010), Cina (Zhang et al., 2012) dan Kanada (Arora et al., 2013) terus meningkat. Di Indonesia berdasarkan riset kesehatan dasar (Riskesdas) 2013 prevalensi CKD sebesar 0,2\%, sedangkan di Yogyakarta sebesar 0,3\%. Prevalensi CKD meningkat seiring bertambahnya usia dengan kategori 5574 tahun $(0,5 \%)$, tertinggi pada kelompok usia $\geq 75$ tahun $(0,6 \%)$ (Kemenkes RI, 2013).

Pada usia lanjut tidak jarang ditemukan lebih dari satu penyakit kronis (multimorbiditas). Multimorbiditas pada pasien usia lanjut dengan CKD merupakan hal yang biasa terjadi, adapun komorbid biasanya disebabkan karena komplikasi dari CKD maupun penyebab utama CKD. Namun, tidak jarang adanya komorbid tidak berhubungan langsung dengan penyakit utamanya (CKD). Komorbid yang biasa terjadi pada pasien usia lanjut dengan CKD seperti diabetes melitus, hipertensi, penyakit karidovaskular, gagal jantung kongestif, penyakit paru, dan lain-lain (KDOQI, 2012). Pasien dengan multimorbiditas biasanya menerima obat dengan jumlah yang lebih banyak (polifarmasi). Penelitian di Irlandia, Eropa dan Amerika menunjukan lebih dari $40 \%$ pasien usia lanjut yang menderita penyakit kronis menerima lebih dari 5 (lima) obat secara bersamaan (Neughton et al., 2006 \& Fialova et al., 2005).

Dibeberapa negara PIMs sudah banyak teridentifikasi pada pasien usia lanjut, di Swiss penelitian yang dilakukan oleh Pierre et al. (2010) dari 150 sampel penelitianya ditemukan 116 pasien (77\%) yang teridentifikasi PIMs. Penelitian yang dilakukan oleh Jones \& Bhandari (2013) menunjukan tingkat kejadian PIMs pada pasien usia lanjut dengan CKD sebesar 56\%. PIMs pada pasien usia lanjut dengan gagal ginjal kronik di Jepang mencapai 57\% (Kondo et al., 2014). Beberapa metode dan kriteria untuk mengidentifikasi PIMs telah di perkenalkan secara internasional dan banyak digunakan sebagai indikator PIMs. beberapa kriteria yang banyak digunakan adalah Beers Criteria dan STOPP Criteria.

Pasien usia lanjut dengan penyakit ginjal kronis atau gagal ginjal kronis dan menjalani hemodialisa serta adanya komorbid, dapat mingkatkan jumlah obat yang diresepkan sehingga kemungkinan berpengaruh terhadap tingkat kejadian PIMs (Gallieni \& Cancarini, 2014). Menurut Momin et al. (2013) terdapat hubungan yang signifikan antara besarnya jumlah obat ( $>6$ obat) dan tingkat kejadian PIMs pada usia lanjut. Penelitian ini bertujuan untuk mengkaji hubungan jumlah obat yang diresepkan dengan kejadian PIMs pada pasien usia lanjut yang menderita penyakit ginjal kronis di RS PKU Muhammadiyah Yogyakarta

\section{METODE PENELITIAN Desain penelitian}

Rancangan penelitian yang digunakan adalah cross sectional study, penelitian dilakukan pada bulan Februari 2015. Kriteria inklusi dalam penelitian ini usia 60 tahun, didiagnosa CKD/CRF, menjalani hemodialisa, dan mendapatkan terapi obat. 


\section{Pengumpulan data}

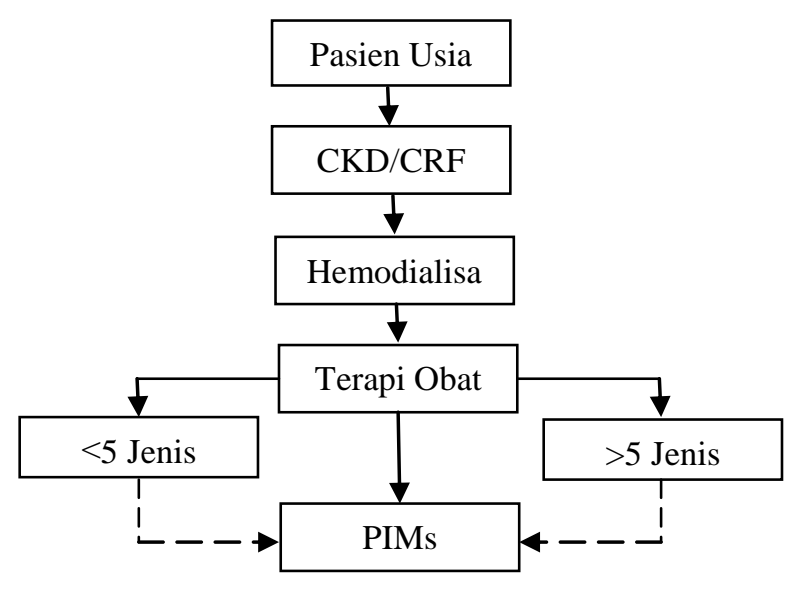

Data yang diambil berupa data primer dan data sekunder. Pasien usia $\geq 60$ tahun yang menderita penyakit ginjal kronis dan menjalani hemodialisa di RS PKU Muhammadiyah yogyakarta menjadi sampel dalam penelitian ini. Pengumpulan data dilakukan dengan mengkaji kesehatan sampel dengan wawancara langsung dan mengkaji rekam medis yang ada di unit hemodialisa maupun yang ada di unit rekam medis menggunakan lembar pengumpul data. Data yang dikumpulkan berupa karakteristik dasar pasien seperti usia, jenis kelamin, berat badan, pendidikan, pekerjaan, pembiayaan, komorbid, jenis obat, jumlah obat, kriteria PIMs.

PIMs adalah ketidaktepatan pengobatan (overprescribing/misprescribing) pada subyek berdasarkan kriteria STOPP. Kriteria STOPP meliputi interaksi obat dengan obat, interaksi obat dengan penyakit, obat yang mempengaruhi kondisi klinis pasien, dan duplikasi golongan obat. Persentase kejadian PIMs ditentukan berdasarkan perbandingan jumlah subyek yang teridentifikasi PIMs dengan jumlah subyek penelitian. Jumlah obat yang diresepkan adalah jumlah obat yang diberikan dan digunakan pasien untuk pengobatan penyakit utama maupun komorbid dalam jangka panjang maupun jangka pendek yang terdapat dalam buku kendali obat tiap pasien. Jumlah obat dikategorikan menjadi $\leq 5$ dan $>5$.

\section{Analisis data}

Untuk menetapkan PIMs digunakan kriteria 65 kriteria STOPP (terlampir). Berdasarkan kriteria STOPP penilaian PIMs dilakukan berdasarkan kondisi klinis pasien (subyektif/obyektif), dosis, interaksi obat-obat, interaksi obat-penyakit utama maupun komorbid, serta duplikasi golongan obat. Data yang dikumpulkan kemudian dianalisa berdasarkan karakteristik sampel menggunakan uji deskriptif dan korelasi antar variabel menggunakan uji chi square.

\section{HASIL DAN PEMBAHASAN}

Dari 56 populasi pasien usia lanjut yang menjalani hemodialisa, terdapat 53 sampel yang masuk dalam kriteria penelitian. Semua sampel yang masuk dalam kriteria penelitian ini berusia $>60$ tahun. Berdasarkan jenis kelamin, pasien laki-laki yang menjadi sampel paling besar dalam penelitian ini yaitu 33 orang $(62,3 \%)$ sedangkan perempuan 20 orang (37,7\%). tingkat pendidikan SLTA berjumlah paling tinggi $(37,7 \%)$ kemudian diikuti dengan sarjana $(20,8 \%)$, SD $(18,9 \%)$, SLTP $(13,2 \%)$, Diploma $(7,5 \%)$ dan tidak bersekolah $(1,9 \%)$. Ditinjau dari pekerjaan sebagian besar sampel adalah swasta yang meliputi petani, buruh, ibu rumah tangga, dan wiraswasta $(56,6 \%)$, sedangkan pegawai negeri sipil (PNS) sebesar 43,3\%. Jaminan kesehatan pemerintah merupakan jaminan kesehatan paling dominan yang dipilih pasien di unit hemodialisa RS PKU Muhammadiyah Yogyakarta $(98,1 \%)$, sedangkan jaminan kesehatan mandiri hanya 1,9\%. Demografi sampel dapat dilihat dalam Tabel I. 
Tabel I. Karakteristik demografi pasien usia lanjut yang menderita CKD dan menjalani Hemodialisa di RS PKU Muhammadiyah Yogyakarta

\begin{tabular}{llcl}
\hline No & Karakteristik & Frekuensi $\left(\sum\right)$ & Persentase ( \% ) \\
\hline 1 & Usia $>60$ Tahun & 53 & 100 \\
2 & Jenis kelamin & & \\
& a. Laki - laki & 33 & 62,3 \\
& b. Perempuan & 20 & 37,7 \\
3 & Pendidikan & & \\
& a. Tidak sekolah & 1 & 1,9 \\
& b. SD & 10 & 18,9 \\
& c. SLTP & 7 & 13,2 \\
& d. SLTA & 20 & 37,7 \\
& e. Diploma & 4 & 7,5 \\
& f. Sarjana & 11 & 20,8 \\
4 & Pekerjaan & & \\
& a. Swasta & 30 & 56,6 \\
& b. PNS & 23 & 43,4 \\
& Jaminan & & \\
& a. Mandiri & 1 & 1,9 \\
& b. Pemerintah & 52 & 98,1 \\
\hline
\end{tabular}

Tabel II. Karakteristik pasien berdasarkan berat badan, komorbid, dan jumlah obat yang diresepkan

\begin{tabular}{lllllll}
\hline No & Karakteristik & Jumlah & Mean & SD & $\begin{array}{l}\text { Min- } \\
\text { Max }\end{array}$ & Median \\
\hline 1 & BB & 53 & 58,8 & 11,1 & $38-88$ & 58 \\
2 & Komorbid & 53 & 1,3 & 0,8 & $1-5$ & 1 \\
3 & Jumlah Obat & 53 & 7,8 & 2,8 & $4-16$ & 7 \\
\hline
\end{tabular}

Rata-rata berat badan responden $58,78 \mathrm{Kg}$ dengan berat minimum $38 \mathrm{Kg}$ dan maksimum 88 $\mathrm{Kg}$. Berat badan menjadi hal yang penting pada pasien penyakit ginjal kronis dengan dialisis, hal ini berhubungan dengan proses dialisis yang akan dilakukan. Dimana digunakan dalam menentukan volume cairan yang akan didialisis pada saat itu. Diantara dua waktu dialisis biasanya ada penambahan berat badan yang disebut sebagai interdialysis weight gain (IDWG). Menurut Pace (2007), jika IDWG melebihi $4.8 \%$ akan meningkatkan mortalitas meskipun = tidak dinyatakan besarannya. Terdapat hubungan yang signifikan antara IDWG yang tinggi dengan kelebihan cairan dan merupakan prekursor tingginya tekanan darah pre dialisis (Gomez, 2005). Adapun komorbid untuk 53 sampel dalam penelitian ini rata-rata 1,3 dengan jumlah minimal 1 dan maksimal 5 komorbid. Jenis komorbid yang diderita pasien usia lanjut yang menjalani hemodialisa dapat dilihat dalam gambar berikut.

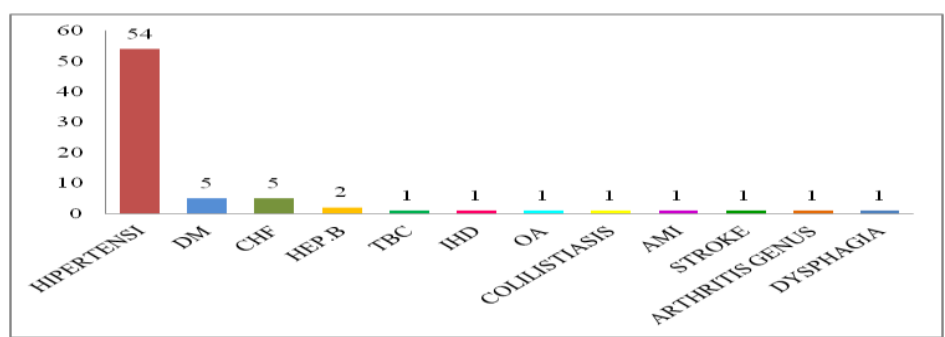

Gambar 1. Komorbid pada pasien usia lanjut yang menderita CKD dan menjalani hemodialisa di RS PKU Muhammadiyah Yogyakarta 
Hipertensi pada pasien CKD dapat menjadi penyebab maupun akibat dari CKD itu sendiri. Sebagai komorbid keberadaan hipertensi dapat meningkatkan risiko penyakit kardiovaskular. Oleh sebab itu sangat penting menjaga tekanan darah pada pasien tersebut, target tekanan darah pada pasien CKD dengan hemodialisis adalah $<140 / 90 \mathrm{mmHg}$ (KDOQI, 2012). Peningkatan tekanan darah predialysis dapat disebabkan beberapa faktor seperti adanya terjadinya ekspansi volume ekstraseluler, kepatuhan pasien terhadap diet asupan garam yang masih rendah, aktivasi sistem renin angiotensinaldosteron dan simpatik yang berlebihan, retensi toksin ureum (dimethylarginine asimetris) yang dapat menyebabkan vasokoknstriksi dan faktor lainya.

Semakin besar jumlah komorbid maka semakin banyak jumlah obat yang diresepkan. Jumlah obat pada masing-masing sampel sangat bervariatif sesuai dengan jumlah komorbid yang diderita pasien, rata-rata jumlah obat yang diresepkan pada 53 sampel yaitu 7,8 dengan jumlah minimal 4 dan maksimal 16 obat.

Berdasarkan tempat aksinya, beberapa obat yang paling banyak diresepkan dan digunakan pasien usia lanjut yang menderita CKD dan menjalani hemodialisa di RS PKU Muhammadiyah Yogyakarta adalah obat-obat yang bekerja pada sistem kardiovaskular, suplemen, obat yang bekerja pada endokrin, nutrisi parenteral, muskuloskeletal dan lainya. Seperti yang dapat dilihat pada gambar dibawah ini.

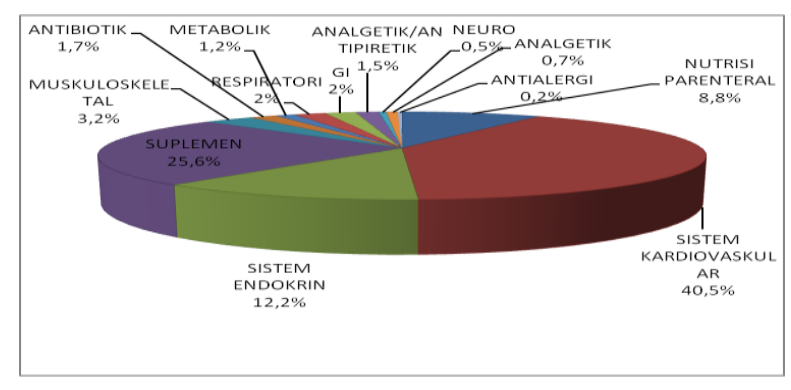
Gambar 2. Persentase obat yang diresepkan pada pasien usia lanjut yang menderita CKD dan
menjalani hemodialisa di RS PKU Muhammadiyah Yogyakarta

Obat kardovaskular merupakan obat yang banyak diresepkan pada pasien hemodialisa, terutama obat-obat antihipertensi, dimana rata-rata pasien menerima 2 (dua) sampai 3 (tiga) kombinasi antihipertensi. Golongan obat antihipertensi yang banyak diresepkan adalah angiotensin reseptor blocker (ARB), calcium chanal blocker (CCB), angiotensin converting enzim inhibitor (ACEI), $\alpha$ blocker dan $\beta$-blocker.Selain itu beberapa obat kardiovaskular lainya adalah diuretik, vasodilator dan antiplatelet. Suplemen menjadi obat terbanyak kedua yang diresepkan pada pasien usia lanjut yang menjalani hemodialisa yaitu sebesar (25,6\%). Jenis suplemen yang banyak digunakan adalah asam folat, vitamin B kompleks dan kalsium. Suplemen tersebut diberikan dengan tujuan tertentu, terutama kalsium ( $\mathrm{CaCo} 3$ atau kalsium asetat) pada pasien CKD digunakan dengan tujuan sebagai pengikat fosfat dan unk memenuhi kebutuhan kalsium pada pasien penyakit ginjal kronis karena adanya bone deseas. Sedangkan asam folat dan vitamin B kompleks digunakan sebagai terapi tambahan anemia. $12,2 \%$ dari jumlah obat yang diresepkan adalah obat-obat sistem endokrin yang banyak diresepkan seperti insulin dan antidiabetik oral, sebagai terapi hiperglikemi pada pasien DM. Sebagian besar pasien hanya menerima insulin sebagai terapi pengontrol kadar gula darah, sedangkan antidiabetik oral (pioglitazon dan gliclasid) kombinasi dengan insulin hanya digunkakan untuk penurunan kadar glukosa secara agresif pada pasien tertentu. Nutrisi parenteral juga menjadi pilihan obat yang diresepkan dan diberikan pada pasien hemodialisa $(8,8 \%)$, jenis nutrisi parenteral yang diresepkan adalah asam amino. Sedangkan 3,2\% obat-obat muskuloskeletal yang digunakan adalah allopurinol. Obat gastrointestinal dan sistem respirasi yang digunakan masing-masing sebesar 2\%. Obat-obat GI yang banyak digunakan adalah antiemetik dan PPI, sedangkan obat-obat untuk sistem respirasi yaitu salbutamol dan fluticason yang digunakan untuk mengatasi sesak pada pasien CKD.

Persentase analgetik/ antipiretik (paracetamol) dalam penelitian ini hanya $1,5 \%$, tujuan penggunaan pada penelitian ini sebagai antipiretik pada pasien-pasien tertentu dengan suhu badan 
$>37^{\circ} \mathrm{C}$. Sedangkan analgetik $(0,7 \%)$ yang digunakan dalam penelitian ini adalah meloxicam. Dimana penggunaan meloxicam pada usia lanjut termasuk dalam kriteria STOPP. Penggunaan obat paling rendah adalah antialergi (cetrizin) $0,2 \%$.

Frekuensi dan persentase kejadian PIMs pada pasien usia lanjut ynag menderita penyakit ginjal kronis di RS PKU Muhammadiyah Yogyakarta berdasarkan jumlah sampel hanya 19\% dengan rata-rata pasien menerima satu PIMs. Hal ini menunjukan bahwa tingkat kejadian PIMs pada penelitian ini sangat rendah. seperti yang dijelaskan dalam gambar berikut.

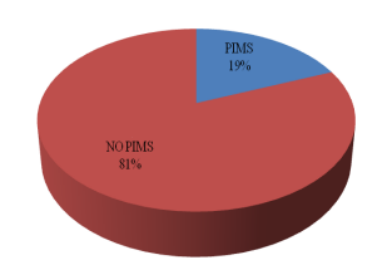

Gambar 3. Persentase PIMs yang teridentifikasi pada pasien usia lanjut yang menderita penyakit ginjal kronis di RS PKU Muhammadiyah Yogyakarta.

Rendahnya PIMs yang teridentifikasi pada penelitian ini menunjukan bahwa penanganan kesehatan pasien usia lanjut terutama yang menjalani hemodialisa di RS PKU Muhammadiyah sudah cukup baik. Pengobatan dilakukan berdasarkan pertimbangan risiko dan manfaat pada pasien usia lanjut. Penggunaan obat yang sifatnya hanya berpotensi memberikan efek merugikan pada pasien usia lanjut tapi secara klinis memberikan keuntungan yang lebih besar, maka masih dapat dibenarkan dengan dukungan teoritis dan bukti yang kuat. Beberapa faktor yang dapat menyebabkan rendahnya PIMs yang teridentifikasi dalam penelitian ini adalah jumlah sampel yang terbatas, tidak terjangkaunya unit pelayanan lain oleh peneliti, adanya kesadaran tenaga kesehatan terhadap obat-obat yang mempunyai resiko tinggi pada pasien usia lanjut, serta adanya interaksi dan komunikasi yang baik antara pasien dan tenaga kesehatan selama perawatan. Sedangkan tingginya PIMs pada pasien usia lanjut dihubungkan dengan beberapa faktor yaitu adanya polifarmasi, gangguan kejiwaan, penyakit serebrovaskular, ketergantungan (Vieira de Lima et al., 2013), gagal jantung, depresi, dan imobilisasi (Wawruch, 2008).

Tabel III. Kriteria PIMs yang teridentifikasi pada pasien usia lanjut yang menderita CKD dan menjalani hemodialisa di RS PKU Muhammadiyah Yogyakarta

\begin{tabular}{llll}
\hline No & Kategori & Frekuensi $\left(\sum\right)$ & Persentase $(\%)$ \\
\hline 1 & Duplikasi Obat & 1 & 10 \\
2 & NSAID & 2 & 20 \\
3 & Aspirin & 7 & 70 \\
\hline
\end{tabular}

Seperti yang digambarkan dalam tabel diatas, kriteria PIMs yang teridentifikasi dalam penelitian ini adalah pengunaan asspirin pada pasien tanpa riwayat penyakit kardiovaskular (70\%), penggunaan NSAID (20\%), dan duplikasi golongan obat (10\%). Penggunaan aspirin pada usia lanjut mempunyai risiko perdarahan yang tinggi dibandingkan dengan pasien dewasa secara umum, oleh sebab itu penggunaan aspirin hanya digunakan untuk pasien dengan penyakit karidovaskuler seperti aterosklerosis atau iskemik. Akan tetapi pada pasien yang menjalani hemodialisa penggunaan aspirin ditujukan sebagai terapi preventif primer aterosklerosis (KDOQI, 2012). Risiko perdarahan dari penggunaan aspirin tergantung dosis yang digunakan, pada dosis rendah ( $<200 \mathrm{mg} / \mathrm{hari}$ ) (Serebruany et al., 2005). Sedangkan pada penelitian ini dosis aspirin yang digunakan rata-rata $80 \mathrm{mg} /$ hari.

NSAID (meloxicam) yang digunakan sampel pada penelitian ini sebagai terapi nyeri muskuloskeletal, pada populasi usia lanjut dapat terjadi peningkatan risiko efek samping seperti ulkus peptik, efek pada sistem saraf pusat, dan bersifak toksisitas pada ginjal meskipun dalam dosis rendah (DIH, 2009). Penggunaan dua agen tersebut diatas diberikan sangat hati-hati kepada pasien usia lanjut karena adanya resiko efek samping yang tinggi, hal tersebut dapat terjadi karena adanya peurunan fungsi fisiologis pada usia lanjut secara alami terutama penurunan fungsi ginjal.

Sedangkan duplikasi golongan obat yang teridentifikasi dalam penelitian ini adalah terapi antihipertensi golongan calcium channel blocker (CCB) seperti Amlodipin dan Nifedipin. Dalam terapi hipertensi untuk kombinasi obat antihipertensi digunakan dari dua golongan obat yang berbeda 
misalnya ARB dikombinasikan dengan CCB, dan lainya. Adanya penggunaan duplikasi golongan obat dapat meningkatkan resiko efek samping.

Tingginya jumlah obat yang diresepkan dapat meningkatkan resiko kejadian efek samping maupun adanya interaksi antar obat dan penyakit serta obat dan obat. Selain itu tingginya jumlah obat yang diresepkan juga dapat mempengaruhi kondisi klinis pasien saat itu sehingga menjadi PIMs. Adapun hubungan jumlah obat yang diresepkan dengan PIMs dapat dilihat dalam tabel berikut.

Tabel IV. Hubungan jumlah obat yang diresepkan dengan PIMs pada pasien usia lanjut yang menderita CKD dan menjalani hemodialisa di RS PKU Muhammadiyah Yogyakarta

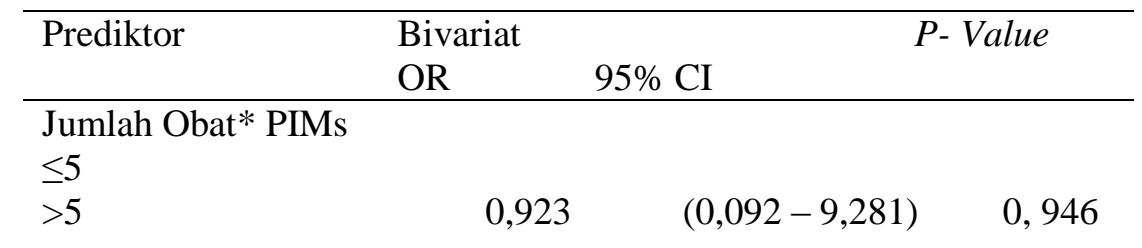

Uji korelasi chi square menunjukan bahwa tidak ada hubungan yang signifikan antara jumlah obat yang diresepkan dengan tingkat kejadian PIMs dengan nilai $P$-Value $>0,05(0,946)$. Artinya tingginya jumlah obat yang diresepkan dalam penelitian ini tidak mempengaruhi penggunaan obat yang benar pada pasien usia lanjut. Beberapa hal yang dapat mempengaruhi hal tersebut adalah rendahnya PIMs yang teridentifikasi, peresepan jenis obat yang hampir sama antar sampel, dan pertimbangan resiko dan manfaat dari penggunaan obat yang sudah cukup baik oleh klinisi .

\section{KETERBATASAN PENELITIAN}

Terbatasnya jumlah sampel dan unit pelayanan lain yang tidak terjangkau menjadi keterbatasan penelitian ini. Selain itu, kurangnya informasi yang disampaikan oleh sampel dan data rekam medis yang kurang lengkap (obyektif) juga menjadi suatu hal yang sulit bagi peneliti untuk mengidentifikasi PIMs.

\section{KESIMPULAN}

Komorbid yang diderita pasien usia lanjut bervariatif, adanya komorbid dapat menyebabkan pemilihan obat yang rasional dan tepat menjadi sangat sulit. Mempertimbangkan tingginya benefit dibandingkan risiko dari penggunaan obat menjadi salah satu tugas klinisi dalam memutuskan pengobatan pada usia lanjut. Hubungan jumah komorbid dengan jumlah obat yang diresepkan linier, semakin banyak jumlah komorbid maka semakin banyak jumlah obat yang diresepkan. Hal ini sudah umum terjadi pada usia lanjut, akan tetapi dengan beberapa penyulit seperti penurunan fungsi fisiologis pada usia lanjut harus tetap diperhatikan sebelum memilih obat yang akan diberikan. Tingkat kejadian PIMs yang teridentifikasi pada penelitian ini sangat rendah, hal ini disebabkan karena kondisi klinis antar pasien tidak jauh berbeda, jenis obat yang diresepkan hampir sama, dan pertimbangan pemilihan obat pada pasien CKD dilakukan sangat hati-hati. Tingginya jumlah obat yang diresepkan pada pasien usia lanjut yang menderita CKD tidak mempengaruhi tingkat kejadian PIMs di RS PKU Muhammadiyah Yogyakarta.

\section{DAFTAR PUSTAKA}

Arora, P., Vasa, P., Brenner, D., Iglar, K., McFarlane, P., Morrison, H., Badawi, A., 2013, Prevalence estimates of chronic kidney disease in Canada: results of a nationally representative survey, CMAJ, 185(9):E417-23.

Fialova, D., Topinková, E., Gambassi, G., Finne-Soveri, H., Jónsson, P.V., Carpenter, I., Schroll, M., Onder, G., Sørbye, L.W., Wagner, C., Reissigová, J., Bernabei, R., 2005, Potentially 
inappropriate medication use among elderly home care patients in Europe. JAMA ; 293 (11): 1348-58.

Gallieni, M., Cancarini, G., 2014, Drugs in the elderly with chronic kidney disease: beware of potentially inappropriate medications, Nephrol Dial Transplant ,0: 1-4.

Hoerger, T.J., Simpson, S.A., Yarnoff, B.O., Pavkov, M.E., Ríos, B.N., Saydah S.H., Williams, D.E., Zhuo, X., 2010, The Future Burden of CKD in the United States: A Simulation Model for the CDC CKD Initiative, Am J Kidney Dis, S0272-6386(14)01363-8.

Jones, S.A., Bhandari, S., 2013, The prevalence of potentially inappropriate medication prescribing in elderly patients with chronic kidney disease, Postgrad Med J, 89(1051):247-50.

Kemenkes RI, 2013, Riset Kesehatan Dasar, di akses tanggal 4 Desember 2014.

Kemenkes RI, 2013, Gambaran Kesehatan Lanjut Usia di Indonesia, Buletin Jendela Data dan Informasi Kesehatan, I;ISSN 2088 - 270X.

Kondo, N., Nakamura, F., Yamazaki, S., Yamamoto, Y., Akizawa, T., Akiba, T., Saito, A., Kurokawa, K., Fukuhara, S., 2014, Prescription of potentially inappropriate medications to elderly hemodialysis patients: prevalence and predictors, Oxford J, doi: 10.1093 .

Momin, T.G., Pandya, R.N., Rana, D.A., dan Patel,V.J., 2013, Use of Potentially Inappropriate Medications in Hospitalized Elderly at A Teaching Hospital: A Comparison Between Beers 2003 and 2012 criteria, Indian Journal of Pharmacology, 45 (6): 603-607.

Naughton, C., Bennett, K., Feely, J., 2006, Prevalence of chronic disease in the elderly based on a national pharmacy claims database. Age \& Ageing ; 35: 633-5.

Pace, R.C. (2007). Fluid Management in Patient on Hemodialysis. Nephrology Nursing Journal, (34):5;557.

Serebruany, V.L., Steinhubl, S.R., Berger, P.B., Malinin, A.I., Baggish, J.S., Bhatt, D.L., Topol, E.J., 2005, Analysis of risk of bleeding complications after different doses of aspirin in 192,036 patients enrolled in 31 randomized controlled trials, Am J Cardiol, 95:1218-22.

Vieira de Lima, T.J., Garbin, C.A.S., Ísper, A.J., Sumida, D.H., Saliba, O., 2013, Potentially inappropriate medications used by the elderly: prevalence and risk factors in Brazilian care homes, BMC Geriatrics, 13:52.

Wawruch, M., Fialova, D., Zikavska, M., Wsolova, L., Jezova, D., Kuzelova, M., Liskova, S., Krajcik, S., 2008, Factors influencing the use of potentially inappropriate medication in older patients in Slovakia, J Clin Pharm Ther, 33(4):381-92.

Yenny dan Herwana, E., 2006, Prevalensi penyakit kronis dan kualitas hidup pada lanjut usia di Jakarta Selatan, Universa Medicina, 25;4;164-171.

Zhang, L., Wang, F., Wang, L., Wang, W., Liu, B., Liu, J., Chen, M., He, Q., Liao, Y., Yu, X., Chen, N., Zhang, J.E., Hu, Z., Liu, F., Hong, D., Ma, L., Liu, H., Zhou, X., Chen, J., Pan, L., Chen, W., Wang, W., Li, X., Wang, H., 2012, Prevalence of chronic kidney disease in China: a cross-sectional survey, Lancet, 379(9818):815-22. 